\title{
Green synthesis of silver nanoparticles using fresh water green alga Pithophora oedogonia (Mont.) Wittrock and evaluation of their antibacterial activity
}

\author{
Sankar Narayan Sinha • Dipak Paul • \\ Nilu Halder · Dipta Sengupta · Samir Kumar Patra
}

Received: 1 August 2014/Accepted: 26 September 2014/Published online: 9 October 2014

(C) The Author(s) 2014. This article is published with open access at Springerlink.com

\begin{abstract}
In the present study, we report the aqueous extract of Pithophora oedogonia to produce silver nanoparticles (AgNPs) by reduction of silver nitrate. It was noted that synthesis process was considerably rapid and silver nanoparticles were generated within few minutes of silver ions coming in contact with the algal extract. A peak at $445 \mathrm{~nm}$ corresponding to the plasmon absorbance of AgNPs was noted in the UV-vis spectrum of the aqueous medium that contained silver ions. Scanning electron microscopic (SEM) and dynamic light scattering analysis of colloidal AgNPs indicated the size of $34.03 \mathrm{~nm}$. Energydispersive $\mathrm{X}$-ray spectroscopy revealed strong signals in the silver region and confirmed of the AgNPs. Fourier transform infrared spectroscopic analysis of the nanoparticles indicated the presence of protein which was regarding a capping agent surrounding the AgNPs. Moreover, the antibacterial activity of synthesized nanoparticles exhibited potential inhibitory activity against seven tested pathogenic bacteria.
\end{abstract}

Keywords Green synthesis - Silver nanoparticles · Pithophora oedogonia · Antibacterial activity

S. N. Sinha $(\bowtie) \cdot$ D. Paul · N. Halder

Environmental Microbiology Research Laboratory,

Department of Botany, University of Kalyani, Kalyani 741235,

West Bengal, India

e-mail: sinhasn62@yahoo.co.in

D. Sengupta $\cdot$ S. K. Patra

Epigenetics and Cancer Research Laboratory, Department of Life Science, National Institute of Technology,

Rourkela 769008, Odisha, India

\section{Introduction}

The field of nanotechnology is one among the foremost important and active areas of research in modern science. Nanotechnology deals with the formulation of experimental processes for the synthesis of nanoparticles with different sizes and shapes (Mahasneh 2013). The application of nanoparticles, usually ranging from 1 to $100 \mathrm{~nm}$, is a developing and interesting area of nanotechnology (Dahl et al. 2007). Nanoparticles synthesized using metals have received extensive attention in recent years because of their remarkable properties and wide range of applications in catalysis (Paul et al. 2014), plasmonics (Khlebtsov and Dykman 2010), optoelectronics (Muruganandam et al. 2014), biological sensor (Venkatesan and Santhanalakshmi 2014), water treatment (Con and Loan 2011) and pharmaceutical applications (Ravichandran 2009). To date, metallic nanoparticles are mostly prepared from noble metals, i.e. silver (Vankar and Shukla 2012), gold (Dash et al. 2014), copper, zinc and titanium (Schabes-Retchkiman et al. 2006) as well from cadmium (Suresh 2014), iron (Behera et al. 2013) and alginate (Asadi 2014). Among the noble metals, silver (Ag) is the metal of choice in the field of biological system, living organisms and medicine (Parashar et al. 2009). It is generally recognized that silver nanoparticles may adhere to the cell wall and damage the cell wall permeability. The cellular DNA and protein are destroyed by interaction of nanoparticles with the phosphorus of DNA and sulphur containing amino acids of protein (Elumalai et al. 2010). Different types of methods are available for the synthesis of silver nanoparticles for example, reduction in solutions (Goia and Matijevic 1998), chemical and photochemical reactions in reverse micelles (Taleb et al. 1997), thermal decomposition of silver compounds (Esumi et al. 1990), radiation assisted (Shahriari 
et al. 2011), electrochemical (Li et al. 2008), sonochemical (Moghimi-Rad et al. 2011), microwave assisted (Pal et al. 2014) and recently via green chemistry approach (Gao et al. 2014).

Green synthesis of nanoparticles is an emerging branch of nanotechnology (Roy and Barik 2010). The use of environmentally benign materials like plant extract (Sinha and Paul 2014), bacteria (Seshadri et al. 2012), fungi (Muhsin and Hachim 2014) and marine algae (Kannan et al. 2013) for the synthesis of silver nanoparticles offers numerous benefits of eco-friendliness and compatibility for pharmaceutical and other biomedical applications as they do not use toxic chemicals for the synthesis protocol. Green synthesis are found to be superior over physical and chemical method as it is economically feasible, environmental friendly, scaled up for mass-scale production without any complexity (Goodsell 2004).

There is an urgent need to develop new microbicidal agents as disease causing microbes become gradually resistant to synthetic drugs which poses a great threat to public health. Synthesis of metallic nanoparticles using marine algae has been extensively studied for their antimicrobial properties (Azizi et al. 2013; Kumar et al. 2013; Prasad et al. 2013). However, reports on fresh water algae are lacking. Pithophora oedogonia (Mont.) Wittrock, the 'horse hair' or 'cotton ball alga' is a fresh water green alga of the order Cladophorales. The present study aimed to synthesis of silver nanoparticles from $P$. oedogonia extract and explores the possibilities of exploiting this alga in pharmaceutical industries as a source of antibacterial compounds.

\section{Materials and methods}

\section{Collection of algal material}

The green algae $P$. oedogonia (Mont.) Wittrock was collected from the fresh water pond of town Hoogly, West Bengal, India. Collected sample was immediately brought to the laboratory in new plastic bags containing pond water to prevent evaporation. Algal material was washed thoroughly with tap water and distilled water to remove extraneous materials and shade-dried for 5 days and ovendried at $60{ }^{\circ} \mathrm{C}$ until constant weight was obtained, then ground into fine powder using electric mixer and stored at $4{ }^{\circ} \mathrm{C}$ for future use.

Biosynthesis of silver nanoparticles

About $10 \mathrm{~g}$ of dried, finely powdered $P$. oedogonia was taken in a $250 \mathrm{~mL}$ Erlenmeyer flask along with $100 \mathrm{~mL}$ of sterilized double distilled water and then boiling the mixture for $15 \mathrm{~min}$ at $60{ }^{\circ} \mathrm{C}$. The boiled extract was filtered with Whatman no. 1 filter paper. The filtrate was treated with aqueous $1 \mathrm{mM} \mathrm{AgNO}_{3}$ solution in an Erlenmeyer flask and incubated at room temperature, resulting in the formation of brownish yellow solution indicating the synthesis of silver nanoparticles. Now this silver nanoparticles solution was purified by centrifugation at 15,000 rpm for $20 \mathrm{~min}$ for three times. Supernatant was discarded and the pellet was dissolved in deionised water.

\section{Phytochemical screening of extract}

Phytochemical screening of algal extract was made to check the possible biomolecules involved in the reduction of silver ion to metal Ag. Dried, finely powdered $P$. oedogonia of $10 \mathrm{~g}$ was soaked in $100 \mathrm{~mL}$ of double distilled water to obtain crude extract. The mixture was then centrifuged at 5,000 rpm for $20 \mathrm{~min}$ at $4{ }^{\circ} \mathrm{C}$ and filtered with Whatman no. 1 filter paper. Phytochemical characterization was carried out qualitatively for the presence of alkaloids, flavonoids, carbohydrates, saponins, glycosides, steroids, tannins, terpenoids and protein (Harborne 1973; Kokate et al. 1995).

\section{Characterization of silver nanoparticles}

The reduction of $\mathrm{Ag}^{+}$ions was recorded by measuring the UV-vis spectrum by diluting a small aliquot of the sample with distilled water. The analysis was done using UV-vis spectrophotometer (Shimadzu UV-1601PC) in the range of $300-700 \mathrm{~nm}$. The nanoparticles solution was centrifuged at $10,000 \mathrm{rpm}$ for $15 \mathrm{~min}$ and the resulting suspension was repeated for three times, after that the purified suspension was washed with deionised water to get pure form, i.e., free of proteins/enzymes which are not able to capping the silver nanoparticles. The sample was completely dried at $60{ }^{\circ} \mathrm{C}$. Finally, the dried nanoparticles were examined by Fourier transform infrared spectroscopy (FTIR) (Thermo Nicolet nexus 670 spectrometer of resolution $4 \mathrm{~cm}^{-1}$ ). Scanning Electron Microscopic (SEM) study of AgNPs was done with the help of scanning electron microscope (Model-Hitachi S-4500). Thin films of the sample were made on a carbon-coated copper grid by immersing a very small amount of the sample on the grid. Excess solution was removed with the help of a blotting paper and then the film on the SEM grid was allowed to dry by putting it under a mercury lamp for $5 \mathrm{~min}$. For energy-dispersive X-ray spectroscopic (EDS) analysis, the silver nanoparticles were dehydrated and drop coated on to carbon film and performed on Hitachi S-3400 NSEM instrument equipped with a Thermo EDS attachments. Size distribution of bioreduced AgNPs was measured using dynamic light scattering (DLS) studies. DLS studies of AgNPs on dilution 
with deionized water were recorded with Malvern-Zetasizer (Nano-Z590) instrument.

Screening of antibacterial activity of the synthesized nanoparticles

Antibacterial activity was analysed with synthesized silver nanoparticles by well diffusion method against four Gramnegative (Escherichia coli MTCC 443, Pseudomonas aeruginosa MTCC 2581, Vibrio cholerae MTCC 3904 and Shigella flexneri MTCC 1457) and three Gram-positive (Bacillus subtilis MTCC 441, Staphylococcus aureus MTCC 3160 and Micrococcus luteus MTCC 1538) bacteria. The bacterial cultures were bringing into broth culture for antibacterial assay. Approximately $7 \mathrm{~mm}$ diameter of well was made on Mueller-Hinton Agar plate with the help of sterilized cork borer. The cultures were uniformly spread on culture media with the help of sterile glass spreader. $25 \mu \mathrm{l}$ of synthesized particles were inoculated to the well, and then the plates were incubated in incubator for $37^{\circ} \mathrm{C}$ for $24 \mathrm{~h}$, the zones of inhibition was discussed.

\section{Statistical analyses}

All experiments were carried out in triplicate, and the results were expressed as the mean. Means and standard deviations (SD) were analysed by using the SPSS 13.0 software package.

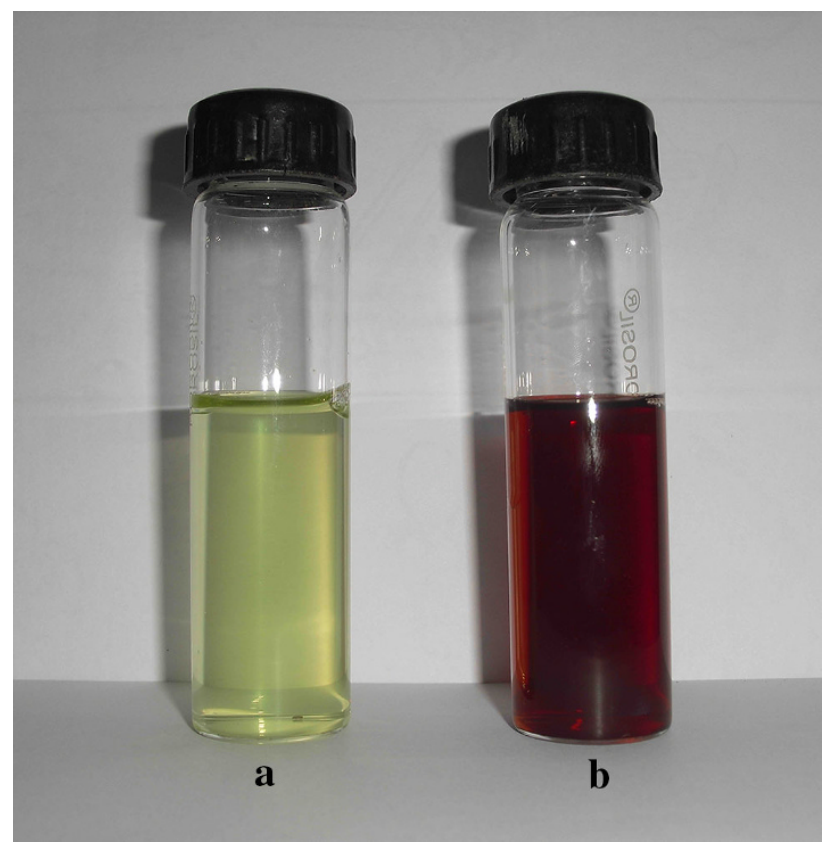

Fig. 1 Colour change during the bioreduction of $\mathrm{AgNO}_{3}$ into AgNPs using Pithophora oedogonia extract: a before synthesis b after synthesis

\section{Results and discussion}

Biosynthesis of silver nanoparticles

When the extract was subjected to $\mathrm{AgNO}_{3}$, the biosynthesis reaction started within few minutes and the colour reaction was observed in which clear $\mathrm{AgNO}_{3}$ solution turned into brown colour which indicates that formation of silver nanoparticles (Swamy et al. 2014) (Fig. 1). This colour difference was due to the reduction of silver ions. Metallic nanoparticles scatter and absorb light at certain wavelengths due to the resonant collective excitations of charge density at the interface between a conductor and an insulator, phenomena known as surface plasmon resonances. The optical response of silver nanoparticles can be regulated by various factors such as particle size, shape and environment, providing a starting point for emerging research fields such as surface plasmon-based photonics or plasmonics (Noguez et al. 2007).

\section{Phytochemical screening}

The preliminary phytochemical analysis of the Pithophora oedogonia extract revealed the presence of carbohydrate, saponins, steroid, tannins, terpenoids and proteins (Table 1). When $P$. oedogonia extract was added to $\mathrm{AgNO}_{3}$ solution, these phytochemicals reduce $\mathrm{Ag}^{+}$ions into $\mathrm{Ag}$ atoms which then join to form AgNPs. The phytochemicals also act as capping agents and thus protect and stabilize the nanoparticles by preventing agglomeration.

\section{Characterization of silver nanoparticles}

The UV-vis spectra of silver nanoparticles synthesized by $P$. oedogonia are shown in Fig. 2a. In the UV-vis absorption spectrum, a distinct peak observed at $445 \mathrm{~nm}$ (Fig. 2). This peak indicated a surface plasmon resonance (SPR), which has already been recorded for various metal

Table 1 Preliminary qualitative analysis of the phytochemicals in the aqueous extracts of Pithophora oedogonia

\begin{tabular}{lc}
\hline Phytochemical constituents & Results \\
\hline Alkaloids & - \\
Flavonoids & - \\
Carbohydrates & + \\
Saponins & + \\
Glycosides & - \\
Steroids & + \\
Tannins & + \\
Proteins & +
\end{tabular}

+ indicates presence or positive reactions, - indicates absence or negative reaction 
Fig. 2 UV-Visible spectra of AgNPs synthesized by treating Pithophora oedogonia extract

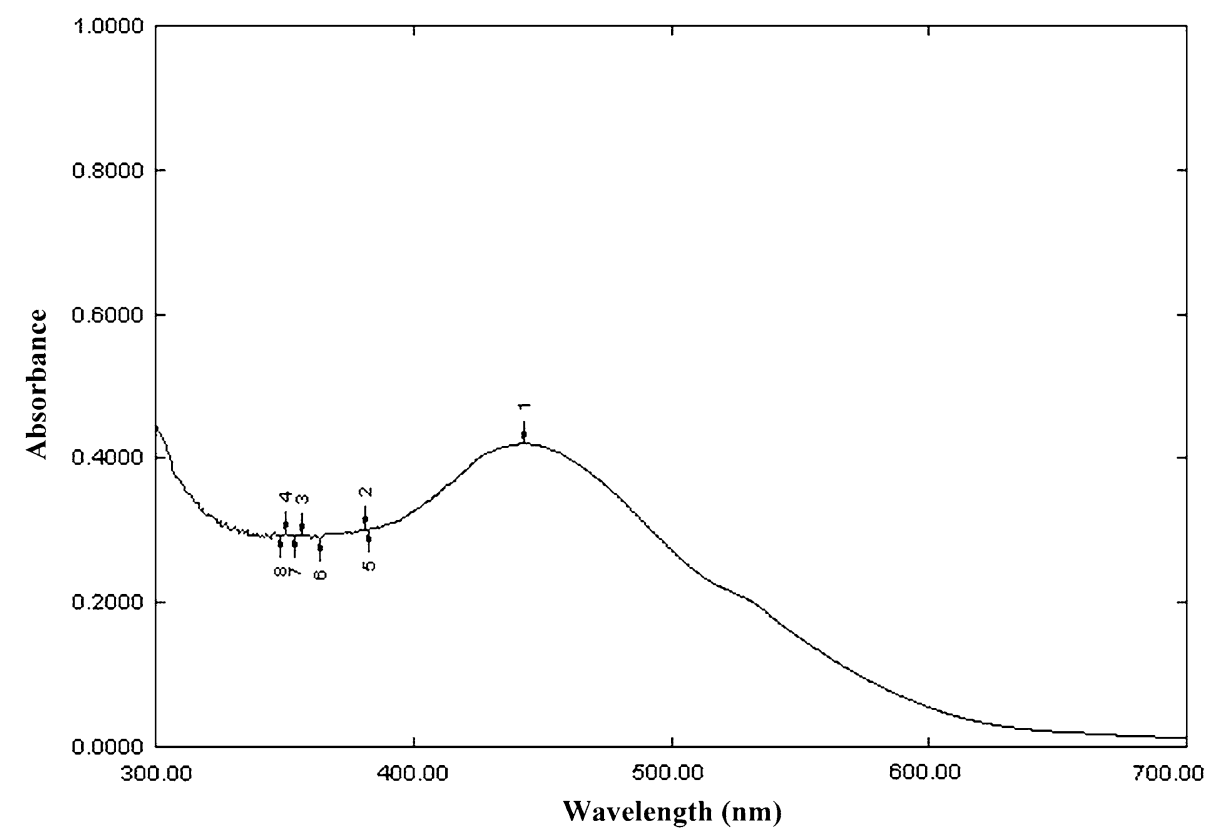

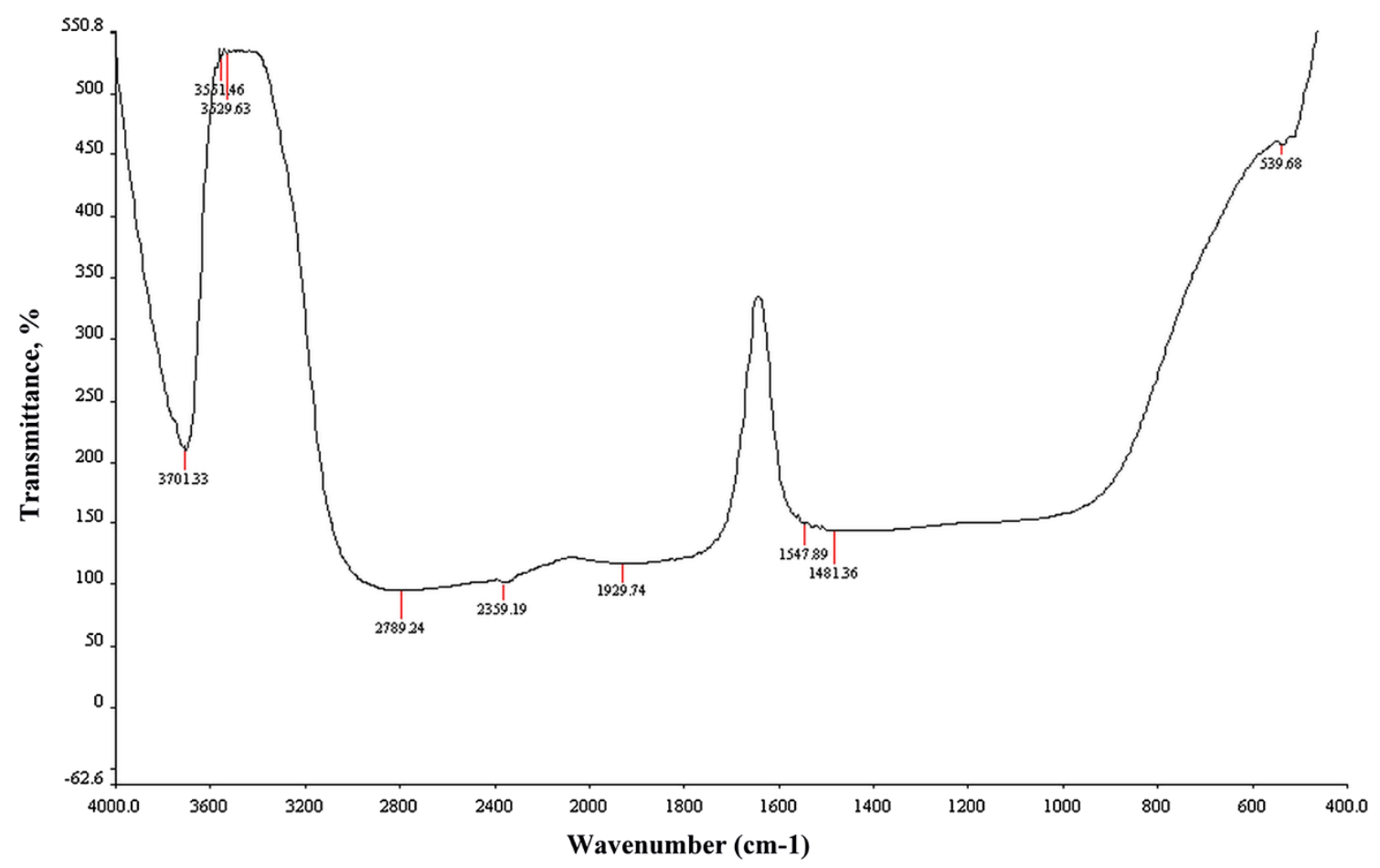

Fig. 3 FTIR spectral pattern of synthesized AgNPs using Pithophora oedogonia extract ranging from 4,000-400 $\mathrm{cm}^{-1}$

nanoparticles which ranged from 2 to $100 \mathrm{~nm}$ in size (Henglein 1993; Ravindra and Rajasab 2014).

The presence of some functional groups as revealed by FTIR spectral analysis is shown in Fig. 3. The FTIR Spectral analysis of silver nanoparticles showed certain common absorption band at $3,701 \mathrm{~cm}^{-1}$, characteristic of $v$ $(\mathrm{N}-\mathrm{H})$ vibrational frequencies. Vibrational peaks at 3,551, 2,789 and $2,359 \mathrm{~cm}^{-1}$ were characteristic of $v(\mathrm{O}-\mathrm{H})$ vibrational frequencies. The vibrational frequencies for $v$ $(\mathrm{C}-\mathrm{O})$ and $v(\mathrm{C}-\mathrm{O}-\mathrm{C})$ were observed in the spectra of the extracts at $1,929,1,547$ and $1,481 \mathrm{~cm}^{-1}$ (Huang et al. 2007; Kannan et al. 2013). Vibrational peaks at $539 \mathrm{~cm}^{-1}$ in extract signified the possibility of an alkyl halide compound. In the synthesized nanoparticles terpenoids, long chain fatty acids and secondary amide derivatives were found to be the possible compounds. Therefore, it may be 


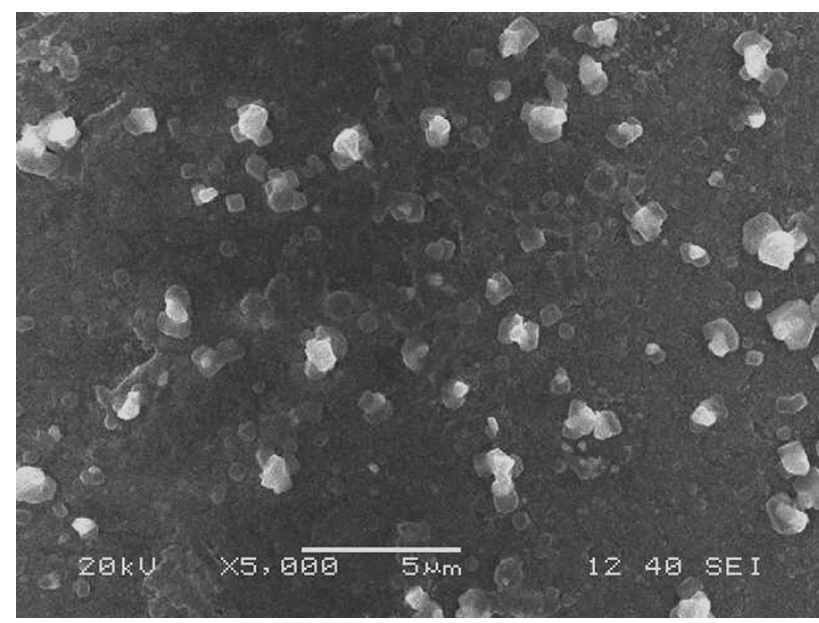

Fig. 4 Representative high magnification scanning electron microscopy (SEM) micrograph of synthesized cubic and hexagon shaped AgNPs

inferred that these biomolecules are responsible for capping and efficient stabilization of synthesized nanoparticles.

SEM analysis of colloidal silver nanoparticles is shown in Fig. 4. The cubical and hexagonal-shaped AgNPs were observed and it was found to be $25-44 \mathrm{~nm}$ range in sizes. Singh et al. (2010) reported that particle size between 10 and $50 \mathrm{~nm}$ in cubic and hexagonal shape synthesized by Argemone mexicana leaf extract. EDS spectrum revealed distinct signals in the silver region and confirm the formation of silver nanoparticles and its elemental nature. EDS spectrum also shows peaks for gold $(\mathrm{Au})$ and oxygen (O) which might be due to the presence of gold as impurities coming from the sample substrate and oxygen peak is from the chamber of EDS (Fig. 5).

The DLS pattern reveals that the mean size distribution of AgNPs was $34.03 \mathrm{~nm}$ and was found to be well dispersed in the colloidal solution with polydispersity index (PDI) of 0.926 (Fig. 6). Kumar et al. (2012) was also reported, the mean size distribution of AgNPs about $45 \mathrm{~nm}$, synthesized using the marine brown seaweed Sargassum tenerrimum.

Screening of antibacterial activity of the synthesized nanoparticles

The nanoparticles showed inhibition zone against all the studied bacterial stain (Fig. 7). Maximum zone of inhibition was found against Pseudomonas aeruginosa (MTCC 2581) $(17.2 \mathrm{~mm}$ ) and followed by Escherichia coli (MTCC 443) $(16.8 \mathrm{~mm})$. The antibacterial activity of the silver nanoparticles may be centred on permeability of bacterial cells due to cell wall layers or its charges (Yu 2007; Chamakura et al. 2011). AgNPs had a considerably minimal bactericidal activity against Gram-positive bacteria compared to Gram-negative one. This is because of high lipopolysaccharide and thick peptidoglycan layer of the Gram-negative bacteria. The negatively charged AgNPs can bind to Gram-negative cell wall better on the contrary. The Gram-positive bacteria are made up of rigid peptidoglycan layer and thus are more stable with minimal binding sites for AgNPs (Fayaz et al. 2010). It was evident from the observations that Gram-negative bacteria are killed more rapidly than Gram-positive bacteria.

\section{Conclusions}

In this study, we have demonstrated first time that use of fresh water algae Pithophora oedogonia (Mont.) Wittrock extract as a reducing agent can effectively produce the cubical and hexagonal shape silver nanoparticles by the green chemistry approach. Characterization of synthesized silver nanoparticles was carried out by UV-vis spectroscopy, FTIR, DLS and SEM equipped with EDS. It is believed that phytochemicals present in the extract of $P$. oedogonia has reduced the silver ions into metallic
Fig. 5 EDS spectrum of synthesized $P$. oedogonia AgNPs

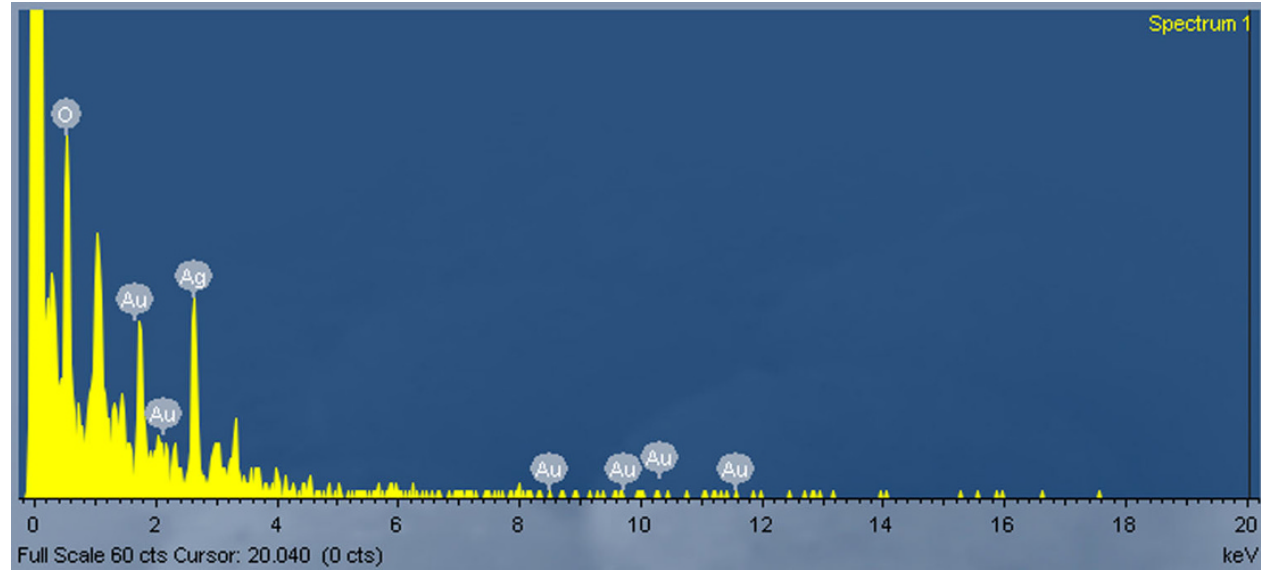

Springer 


\begin{tabular}{|c|c|c|c|c|}
\hline & & Size (r.nm): & \% Intensity & Width $(r . n m):$ \\
\hline Z-Average (r.nm): 4816 & Peak 1: & 34.03 & 100.0 & 0.000 \\
\hline Pdl: 0.926 & Peak 2: & 0.000 & 0.0 & 0.000 \\
\hline Intercept: 2.33 & Peak 3: & 0.000 & 0.0 & 0.000 \\
\hline
\end{tabular}

Result quality : Refer to quality report

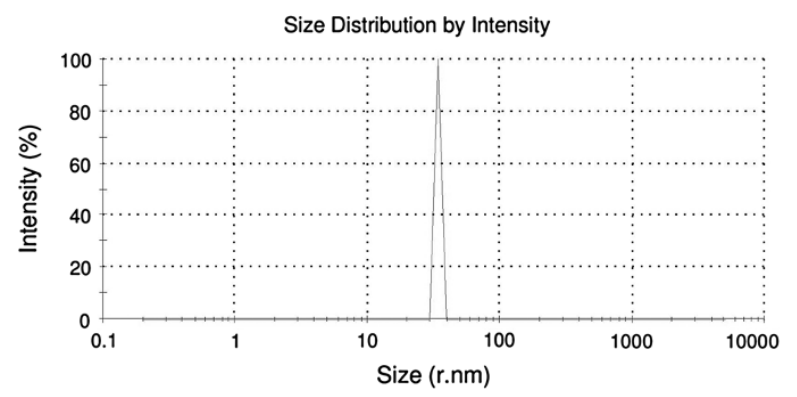

Fig. 6 Dynamic light scattering (DLS) pattern of synthesized AgNPs

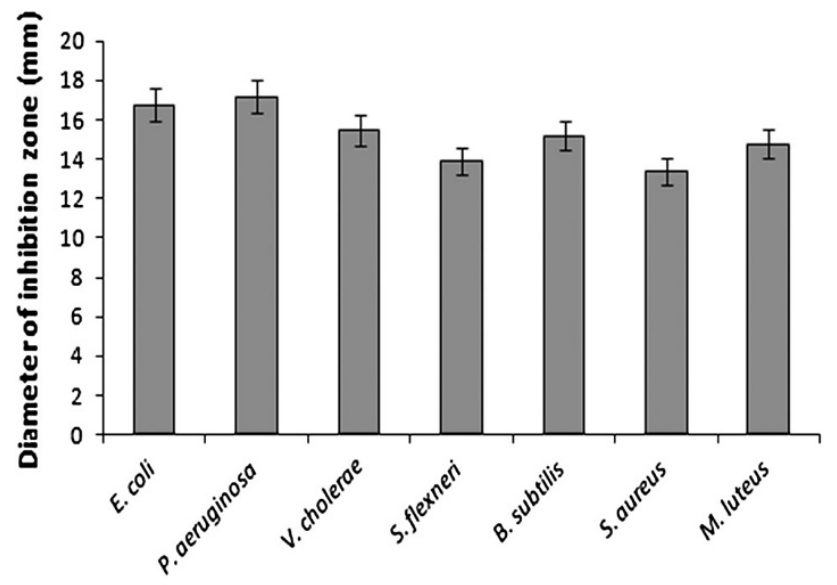

Tested bacterial strains

Fig. 7 Antibacterial activity of synthesized P. oedogonia AgNPs against tested pathogenic bacteria

nanoparticles. The synthesized silver nanoparticles exhibited a strong antibacterial activity against both Gram-negative and Gram-positive bacteria. The synthesis of AgNPs using P. oedogonia (Mont.) Wittrock provides a natural, cost effective, eco-friendly and efficient route for pharmaceutical applications. With the constant increasing of bacterial resistance against known antibiotics in worldwide public health, it is now necessary to find new sources of antimicrobials. Recently there has been a lot of attention focused on producing medicines and products from natural origin. The present research work showed that the synthesized nanoparticles using such algal extracts are ready for the application in the field of nanomedicine against multidrug resistant pathogenic bacteria. The data obtained in this study indicate that it would be important to know the mechanism of action of the biosynthesized nanoparticles before their use in nanomedicine applications.
Acknowledgments Authors are thankful to DST-PURSE for financial support to carry out the research work.

Open Access This article is distributed under the terms of the Creative Commons Attribution License which permits any use, distribution, and reproduction in any medium, provided the original author(s) and the source are credited.

\section{References}

Asadi A (2014) Streptomycin-loaded PLGA-alginate nanoparticles: preparation, characterization, and assessment. Appl Nanosci 4:455-460

Azizi S, Namvar F, Mahdavi M, Ahmad MB, Mohamad R (2013) Biosynthesis of silver nanoparticles using brown marine macroalga, Sargassum muticum aqueous extract. Materials 6:5942-5950

Behera T, Swain P, Rangacharulu PV, Samanta M (2013) Nano-Fe as feed additive improves the hematological and immunological parameters of fish, Labeo rohita $\mathrm{H}$. Appl Nanosci 4:687-694

Chamakura K, Perez-Ballestero R, Luo Z, Bashir S, Liu (2011) Comparison of bactericidal activities of silver nanoparticles with common chemical disinfectants. Colloid Surf B 84:88-96

Con TH, Loan DK (2011) Preparation of silver nano-particles and use as a material for water sterilization. Environ Asia 4:62-66

Dahl JA, Maddux BL, Hutchison JE (2007) Toward greener nanosynthesis. Chem Rev 107:2228-2269

Dash SS, Majumdar R, Sikder AK, Bag BG, Patra BK (2014) Saraca indica bark extract mediated green synthesis of polyshaped gold nanoparticles and its application in catalytic reduction. Appl Nanosci 4:485-490

Elumalai EK, Prasad TNVKV, Kambala V, Nagajyothi PC, David E (2010) Green synthesis of silver nanoparticle using Euphorbia hirta L. and their antifungal activities. Archives Appl Sci Res 2:76-81

Esumi K, Tano T, Torigoe K, Meguro K (1990) Preparation and characterization of bimetallic palladium- copper colloids by thermal decomposition of their acetate compounds in organic solvents. Chem Mater 2:564-567

Fayaz AM, Balaji K, Girilal M, Yadav R, Kalaichelvan PT, Venketesan R (2010) Biogenic synthesis of silver nanoparticles and their synergistic effect with antibiotics: a study against gram-positive and gram- negative bacteria. Nanomed Nanotechnol Biol Med 6:103-109

Gao Y, Huang Q, Su Q, Liu R (2014) Green synthesis of silver nanoparticles at room temperature using kiwifruit juice. Spectrosc Lett 47:790-795

Goia D, Matijevic E (1998) Preparation of monodispersed metal particles. New J Chem 22:1203-1215

Goodsell DS (2004) Bionanotechnology: lessons from nature. Wiley, Hoboken, NJ, USA

Harborne JB (1973) Phytochemical methods. In: Harborne JB (ed) A guide to modern techniques of plant analysis. Chapman and Hall, London

Henglein A (1993) Physicochemical properties of small metal particles in solution: "microelectrode" reactions, chemisorption, composite metal particles, and the atom-to-metal transition. J Phys Chem 97:5457-5471

Huang J, Li Q, Sun D, Lu Y, Su Y, Yang X, Wang H, Wang Y, Shao W, He N, Hong J, Chen C (2007) Biosynthesis of silver and gold nanoparticles by novel sun dried Cinnanonum camphora leaf. Nanotechnology 18:104-105 
Kannan RRR, Arumugam R, Ramya D, Manivannan K, Anantharaman P (2013) Green synthesis of silver nanoparticles using marine macroalga Chaetomorpha linum. Appl Nanosci 3:229-233

Khlebtsov NG, Dykman LA (2010) Optical properties and biomedical applications of plasmonic nanoparticles. J Quant Spectrosc Radiat Transfer 111:1-35

Kokate CK, Purohit AP, Gokhale SB (1995) Pharmacognosy, 3rd edn. Nirali Prakashan, Pune

Kumar P, Senthamil Selvi S, Lakshmi Prabha A, Prem Kumar K, Ganeshkumar RS, Govindaraju M (2012) Synthesis of silver nanoparticles from Sargassum tenerrimum and screening phytochemicals for its antibacterial activity. Nano Biomed Eng 4:12-16

Kumar P, Selvi SS, Govindaraju M (2013) Seaweed-mediated biosynthesis of silver nanoparticles using Gracilaria corticata for its antifungal activity against Candida spp. Appl Nanosci 3:495-500

Li N, Bai X, Zhang S, Gao YA, Zheng L, Zhang J, Ma H (2008) Synthesis of silver nanoparticles in ionic liquid by a simple effective electrochemical method. J Dispers Sci Technol 29:1059-1061

Mahasneh AM (2013) Bionanotechnology: the novel nanoparticles based approach for disease therapy. Jordan J Biol Sci 6:246-251

Moghimi-Rad J, Isfahani TD, Hadi I, Ghalamdaran S, Sabbaghzadeh J, Sharif M (2011) Shape-controlled synthesis of silver particles by surfactant self-assembly under ultrasound radiation. Appl Nanosci 1:27-35

Muhsin TM, Hachim AK (2014) Mycosynthesis and characterization of silver nanoparticles and their activity against some human pathogenic bacteria. World J Microb Biot 30:2081-2090

Muruganandam S, Anbalagan G, Murugadoss G (2014) Optical, electrochemical and thermal properties of $\mathrm{Co}^{2+}$ - doped $\mathrm{CdS}$ nanoparticles using polyvinylpyrrolidone. Appl Nanosci. doi:10. 1007/s13204-014-0313-6

Noguez C (2007) Surface plasmons on metal nanoparticles: the influence of shape and physical environment. J Phys Chem C 111:3806-3819

Pal J, Deb MK, Deshmukh DK (2014) Microwave-assisted synthesis of silver nanoparticles using benzo-18- crown-6 as reducing and stabilizing agent. Appl Nanosci 4:507-510

Parashar V, Parashar R, Sharma B, Pandey AC (2009) Parthenium leaf extract mediated synthesis of silver nanoparticles: a novel approach towards weed utilization. Dig J Nanomater Bios 4:45-50

Paul K, Bag BG, Samanta K (2014) Green coconut (Cocos nucifera Linn.) shell extract mediated size controlled green synthesis of polyshaped gold nanoparticles and its application in catalysis. Appl Nanosci 4:769-775

Prasad TN, Kambala VSR, Naidu R (2013) Phyconanotechnology: synthesis of silver nanoparticles using brown marine algae
Cystophora moniliformis and their characterisation. J Appl Phycol 25:177-182

Ravichandran R (2009) Nanoparticles in drug delivery: potential green nanobiomedicine applications. Int $\mathrm{J}$ Nanotechnol Biomed 1:108-130

Ravindra BK, Rajasab AH (2014) A comparative study on biosynthesis of silver nanoparticles using four different fungal species. Int J Pharm Pharm Sci 6:372-376

Roy N, Barik A (2010) Green synthesis of silver nanoparticles from the unexploited weed resources. Int $J$ Nanotechnol Appl 4:95-101

Schabes-Retchkiman PS, Canizal G, Herrera-Becerra R, Zorrilla C, Liu HB, Ascencio JA (2006) Biosynthesis and characterization of Ti/Ni bimetallic nanoparticles. Opt Mater 29:95-99

Seshadri S, Prakash A, Kowshik M (2012) Biosynthesis of silver nanoparticles by marine bacterium, Idiomarina sp. PR58-8. Bull Mater Sci 35:1201-1205

Shahriari E, Yunus WMM, Talib ZA, Saion E (2011) Thermalinduced non-linearity of $\mathrm{Ag}$ nano-fluid prepared using $\gamma$ radiation method. Sains Malaysiana 40:13-15

Singh A, Jain D, Upadhyay MK, Khandelwal N, Verma HN (2010) Green synthesis of silver nanoparticles using Argemone mexicana leaf extract and evaluation of their antimicrobial activities. Digest J Nanomater Biostruct 5:483-489

Sinha SN, Paul D (2014) Eco-friendly green synthesis and spectrophotometric characterization of silver nanoparticles synthesized using some common Indian spices. Int $\mathrm{J}$ Green Herbal Chem 3:401-408

Suresh S (2014) Studies on the dielectric properties of CdS nanoparticles. Appl Nanosci 4:325-329

Swamy MK, Sudipta KM, Jayanta K, Balasubramanya S (2014) The green synthesis, characterization, and evaluation of the biological activities of silver nanoparticles synthesized from Leptadenia reticulata leaf extract. Appl Nanosci. doi:10.1007/s13204014-0293-6

Taleb A, Petit C, Pileni MP (1997) Synthesis of highly monodisperse silver nanoparticles from AOT reverse micelles: a way to $2 \mathrm{D}$ and 3D self-organization. Chem Mater 9:950-959

Vankar PS, Shukla D (2012) Biosynthesis of silver nanoparticles using lemon leaves extract and its application for antimicrobial finish on fabric. Appl Nanosci 2:163-168

Venkatesan P, Santhanalakshmi J (2014) Synthesis, characterisation and catalytic activity of gold and silver nanoparticles in the biosensor application. J Exp Nanosci 9:293-298

Yu DG (2007) Formation of colloidal silver nanoparticles stabilized by $\mathrm{Na}^{+}$-poly ( $\gamma$-glutamic acid)-silver nitrate complex via chemical reduction process. Colloid Surf B 59:171-178 